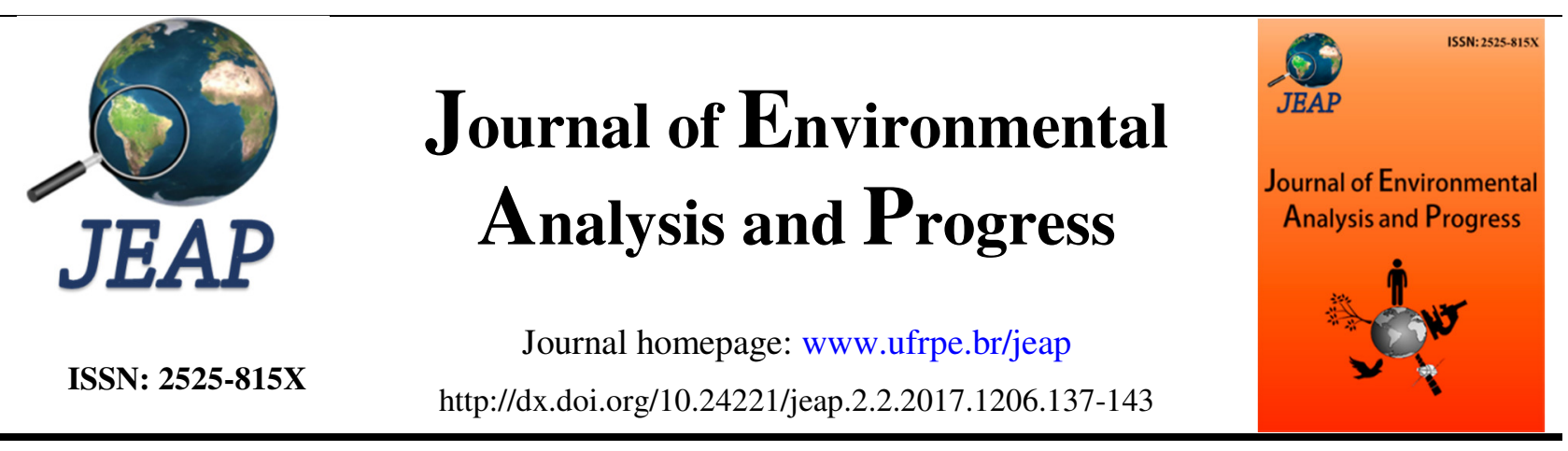

\title{
Uso da água e destinação de resíduos sólidos domiciliares no meio rural
}

\section{Use of water and solid household waste disposal in rural areas}

\author{
Aline Cristina Ferreira Nunes ${ }^{\mathrm{a}}$, Alexsandro Bezerra Correia Bilar ${ }^{\mathrm{a}^{*}}$, Rejane Magalhães de Mendonça \\ Pimentel $^{\mathrm{b}}$ \\ ${ }^{\text {a }}$ Universidade Federal Rural de Pernambuco-UFRPE, Unidade Acadêmica de Serra Talhada-UAST. Av. Gregório Ferraz \\ Nogueira, s/n, José Tomé de Souza Ramos, Serra Talhada, Pernambuco, Brasil. CEP: 56909-535. E-mail: \\ alinenunes_sje@hotmail.com; alexsandrobilar@yahoo.com.br.*Autor correspondente. \\ b UFRPE, Departamento de Biologia-Área de Botânica. Rua Manoel de Medeiros, s/n, Dois Irmãos, Recife, Pernambuco, \\ Brasil. CEP: 52171-900. E-mail: rejanemmpimentel@gmail.com.
}

\section{A R T I C L E I N F O}

Recebido 31 Mar 2017

Aceito 28 Abr 2017

Publicado 02 Mai 2017

\section{A B S T R A C T}

The rational use of water and the correct allocation of household solid waste are sustainable actions beneficial to the environment. In rural areas of Northeastern semiarid region, the little existing water must be treated with zeal and consciousness; environmental education plays a major role in this process. An exploratorydescriptive research with rural students of the elementary school to find out how their families use the water and what is given to solid waste generated daily. It was found that most of the water is stored in tanks and wells and intended for human consumption. It was noted that waste water and a solid household waste of the residents of places are burned or buried. The school studied presented disability in their pedagogical practices because the concepts of sustainability and environmental education are ignored by most students, which reproduce in their homes the incorrect habit not separating garbage.

Keywords: Environmental awareness, environment, sustainability.

\section{R E S U M O}

O uso racional da água e a correta destinação de resíduos sólidos domiciliares são ações sustentáveis, benéficas ao meio ambiente. No meio rural do semiárido nordestino, a pouca água existente deve ser tratada com zelo e consciência; a educação ambiental possui um papel importante nesse processo. Realizou-se uma pesquisa exploratório-descritiva com estudantes rurais do ensino fundamental com o intuito de averiguar como suas famílias utilizam a água e que destino é dado aos resíduos sólidos gerados diariamente. Verificou-se que a maior parte da água é armazenada em cisternas e poços e destinada ao consumo humano. Constatou-se desperdício dessa água e que os resíduos sólidos domiciliares dos moradores de sítios são queimados ou enterrados. A escola estudada apresentou deficiência em suas práticas pedagógicas, pois os conceitos de sustentabilidade e educação ambiental são ignorados pela maioria dos discentes, os quais reproduzem em suas residências o hábito incorreto de não separar o lixo.

Palavras-Chave: Consciência ambiental, meio ambiente, sustentabilidade.

\section{Introdução}

De acordo com Oliveira \& Carvalho (2003), apenas cerca de 3\% da água existente na Terra é doce, sendo que boa parte dela está concentrada nas geleiras e, secundariamente, em grandes profundidades, tornando sua captação economicamente dispendiosa; daí a urgente necessidade de protegê-la e/ou usá-la de maneira racional. Ainda segundo Oliveira \& Carvalho (2003), o Brasil dispõe de $8 \%$ do total de água doce 
superficial do planeta, porém, a sua maior parte, perto de $80 \%$, está localizada na região Amazônica e os $20 \%$ restantes distribuem-se desigualmente pelo restante do país, atendendo $95 \%$ da população.

No semiárido nordestino, bioma Caatinga, há uma enorme escassez de recursos hídricos, pois as precipitações médias anuais são inferiores a $800 \mathrm{~mm}$ e há elevada evaporação devido às altas temperaturas, que chegam a superar $40^{\circ} \mathrm{C}$ em determinados períodos do ano (Moura, 2015). Além disso, no meio rural, a pouca água existente para o consumo humano, também é destinada à agropecuária.

Para conviver com os longos períodos de estiagem, as populações locais armazenam água em açudes, barreiros, cisternas e barragens subterrâneas, assim como constroem poços amazonas ou cacimbões (Rebouças, 2002; Lima, Silva \& Sampaio, 2011; Freitas et al., 2012; Silva et al., 2013). Todavia, essas estratégias são meramente paliativas diante dos enormes esforços que esses habitantes de zonas rurais do Nordeste brasileiro enfrentam diariamente para ter acesso a esse "líquido precioso" (Cirillo, Góes \& Asfora, 2007; Botto, Mota \& Ceballos, 2009).

Os resíduos sólidos domiciliares descartados indevidamente são levados pela água da chuva para dentro desses locais de armazenamento, os quais muitas vezes não recebem tratamento adequado para a eliminação de micro-organismos patogênicos. Segundo Ribeiro \& Lima (2000), ao serem dispostos inadequadamente no solo, esses resíduos tendem a poluir até mesmo as águas subterrâneas causando prejuízos ambientais e à saúde humana. Trata-se, portanto, de um grave problema ambiental que requer a efetivação de políticas públicas específicas, como a criação e a implementação de planos de ação governamental.

Conforme Oliveira \& Carvalho (2003), o saneamento básico está voltado para os serviços de: abastecimento de água, disposição de esgotos sanitários e principalmente com $o$ acondicionamento, coleta, transporte e destinação dos resíduos sólidos (lixo).

A Lei $n^{\circ} 12.305 / 2010$, que instituiu a Política Nacional de Resíduos Sólidos (PNRS), foi concebida como um instrumento essencial na busca de soluções para o mau destino dado aos resíduos sólidos, um dos mais graves problemas ambientais brasileiros (Brasil, 2010). Essa legislação determinou a criação de planos municipais de gestão integrada de resíduos sólidos e a extinção dos lixões a céu aberto até 02 de agosto de 2014, no entanto, como muitos municípios brasileiros não cumpriram essa determinação, encontra-se em tramitação na Câmara dos deputados o Projeto de
Lei $n^{\circ}$. 2.289/2015 que propõe novos prazos para a extinção dos lixões, quais sejam: até 31 de julho de 2018, para capitais e regiões metropolitanas se adequarem; até 31 de julho de 2019, para municípios com população superior a $100 \mathrm{mil}$ habitantes; até 31 de julho de 2020, para municípios com população entre 50 mil e 100 mil habitantes e; até 31 de julho de 2021, para aqueles com população inferior a 50 mil habitantes (Brasil, 2015).

Para Lisboa, Heller \& Silveira (2013), as principais dificuldades adquiridas ao longo do tempo para a elaboração desses planos, assim como os de saneamento são a indisponibilidade de recursos financeiros e a limitação quanto à qualificação profissional e capacidade técnica municipal. Contudo, ao superar o primeiro obstáculo, a qualificação profissional pode ser parcialmente resolvida mediante realização de capacitação e contratação de profissionais, o que pode do mesmo modo superar as dificuldades metodológicas.

Dentre as principais atividades de saneamento estão à coleta e o tratamento de resíduos das atividades humanas tanto sólidos quanto líquidos (lixo e esgoto), prevenir a poluição das águas de rios e outros mananciais (incluindo as águas subterrâneas), garantir a qualidade da água utilizada pelas populações para consumo, bem como seu fornecimento de qualidade, além do controle de vetores (Ribeiro \& Rooke, 2010).

Entretanto, o enfrentamento dessa problemática também requer uma maior consciência ambiental por parte da população rural. Pois, de acordo com Mucelin \& Bellini (2008), costumes e hábitos inadequados relativos ao uso da água e à produção de resíduos sólidos domiciliares ocasionam prejuízos ambientais, bem como à qualidade de vida das pessoas.

A Política Nacional de Educação Ambiental Brasileira, instituída pela Lei $\mathrm{n}^{\circ}$ 9.795/1999 e regulamentada pelo Decreto $\mathrm{n}^{\circ}$, 4.281/2002 destaca o desenvolvimento de ações e práticas educativas voltadas à sensibilização da população, à organização da sociedade em prol das questões ambientais e à defesa da qualidade de vida e do meio (Brasil, 1999; 2002).

Avaliar o entendimento que crianças e adolescentes possuem acerca dos problemas relacionados ao uso inadequado da água e da destinação errônea de resíduos sólidos, especialmente no meio rural, pode gerar novas formas de abordar esse assunto e de propor ações geradoras de hábitos e comportamento sustentáveis (Santos \& Barreto, 2014).

A educação ambiental, no âmbito escolar, pode contribuir bastante com essa mudança 
atitudinal, uma vez que se propõe a formar cidadãos ambientalmente conscientes, trabalhar valores constitutivos e formar uma consciência ambiental saudável (Brasileiro \& Dias, 2013).

Segundo Reis Júnior (2003), existe uma grande lacuna na formação ambiental das crianças, na educação para a cidadania e para o respeito ao ambiente, pois os educadores, em geral, não atribuem ao tema à devida importância, ou sentemse despreparados para lidar com essas questões, por conseguinte, a educação ambiental tem sido tratada de forma pontual, restringindo-se às informações dos livros didáticos, às datas comemorativas e, em algumas escolas, ao plantio de hortas e à coleta seletiva do lixo.

Nesse contexto cabem as seguintes indagações: i - os estudantes rurais do ensino fundamental evitam o desperdício de água em suas residências? ii - esses estudantes promovem uma destinação adequada dos resíduos sólidos gerados em suas casas e aprendem esse hábito em seu ambiente escolar?

Em função destes questionamentos, o objetivo principal deste estudo foi avaliar, sob a ótica dos estudantes rurais do ensino fundamental, de que forma suas famílias fazem uso da água e quais o encaminhamento dado aos resíduos sólidos domiciliares gerados diariamente.

\section{Material e Métodos}

Área de estudo

O local de estudo foi a Escola Municipal Manoel da Costa (Figura 1), localizada em São José do Egito-PE, que funciona nos turnos matutino e vespertino, possui 185 estudantes matriculados em 12 turmas da educação infantil ao ensino fundamental, o que corresponde a uma média geral de 15 estudantes por turma.
A escola está localizada no povoado Curralinho, zona rural do município de São José do Egito, na mesorregião do Sertão Pernambucano, microrregião do Pajeú, coordenadas geográficas $07^{\circ} 28^{\prime} 44^{\prime \prime} \mathrm{S} \mathrm{37} 16^{\circ} 28^{\prime \prime} \mathrm{O}$ (Figura 2), com uma área territorial de $780 \mathrm{~km}^{2}$, limitando-se ao Norte com Itapetim e Brejinho, ao Sul com Ingazeira e Tuparetama, a Leste com o estado da Paraíba e ao Oeste com Tabira e Santa Terezinha; e uma população de, aproximadamente, 31.829 habitantes, clima semiárido quente, com temperaturas variando entre $20^{\circ} \mathrm{C}$ e $36^{\circ} \mathrm{C}$ (IBGE, 2010).

\section{Procedimentos para coleta e análise dos dados}

$\mathrm{O}$ estudo foi exploratório-descritivo, com revisão de literatura e uma pesquisa de campo (Marconi \& Lakatos, 2003; Gil, 2007, 2009).

Foi aplicado um questionário semiestruturado contendo perguntas objetivas e subjetivas em quatro turmas, do $6^{\circ}$ ao $9^{\circ}$ ano do ensino fundamental, escolhidas por possuírem os estudantes que estão há mais tempo na escola.

Ao todo, 58 estudantes responderam o questionário, durante dias letivos normais dos meses de julho e agosto do ano de 2014. Adotou-se uma análise quanti-qualitativa para a análise dos dados (Creswell, 2007).

A Direção da escola autorizou a realização desta pesquisa, a qual contou com a anuência dos estudantes, que participaram voluntariamente, foram informados acerca dos objetivos e métodos do estudo e que os dados obtidos seriam utilizados para fins meramente acadêmicos, em conformidade com as diretrizes da Comissão Nacional de Ética em Pesquisa - CONEP (Brasil, 2012).

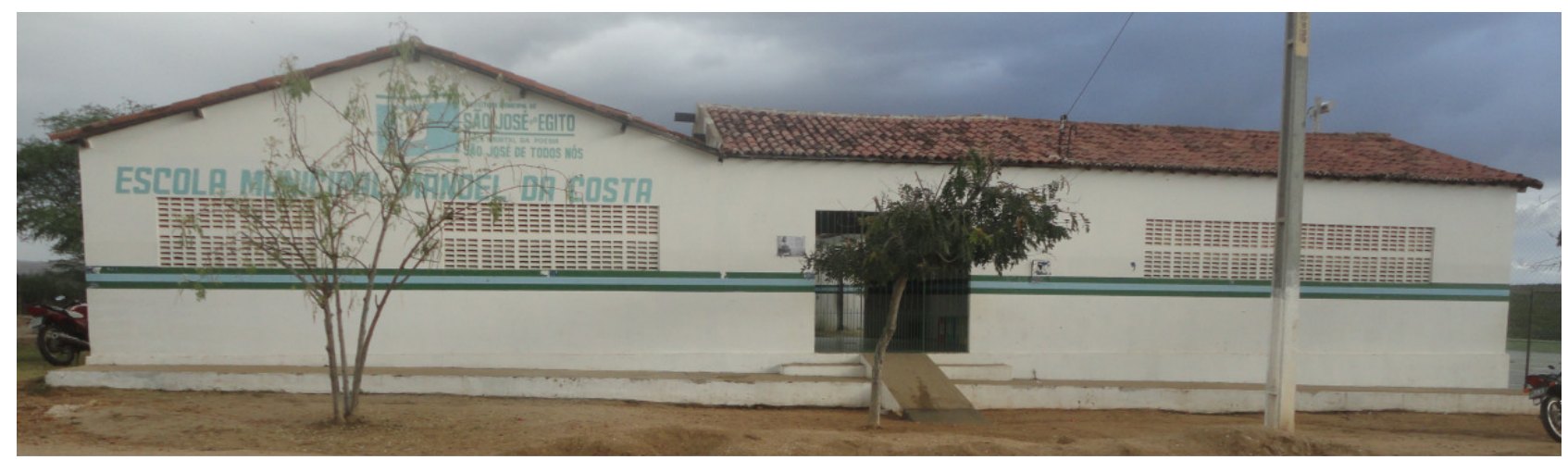

Figura 1. Fachada da Escola Municipal Manoel da Costa. Fonte: Nunes, A. C. F. (2014). 


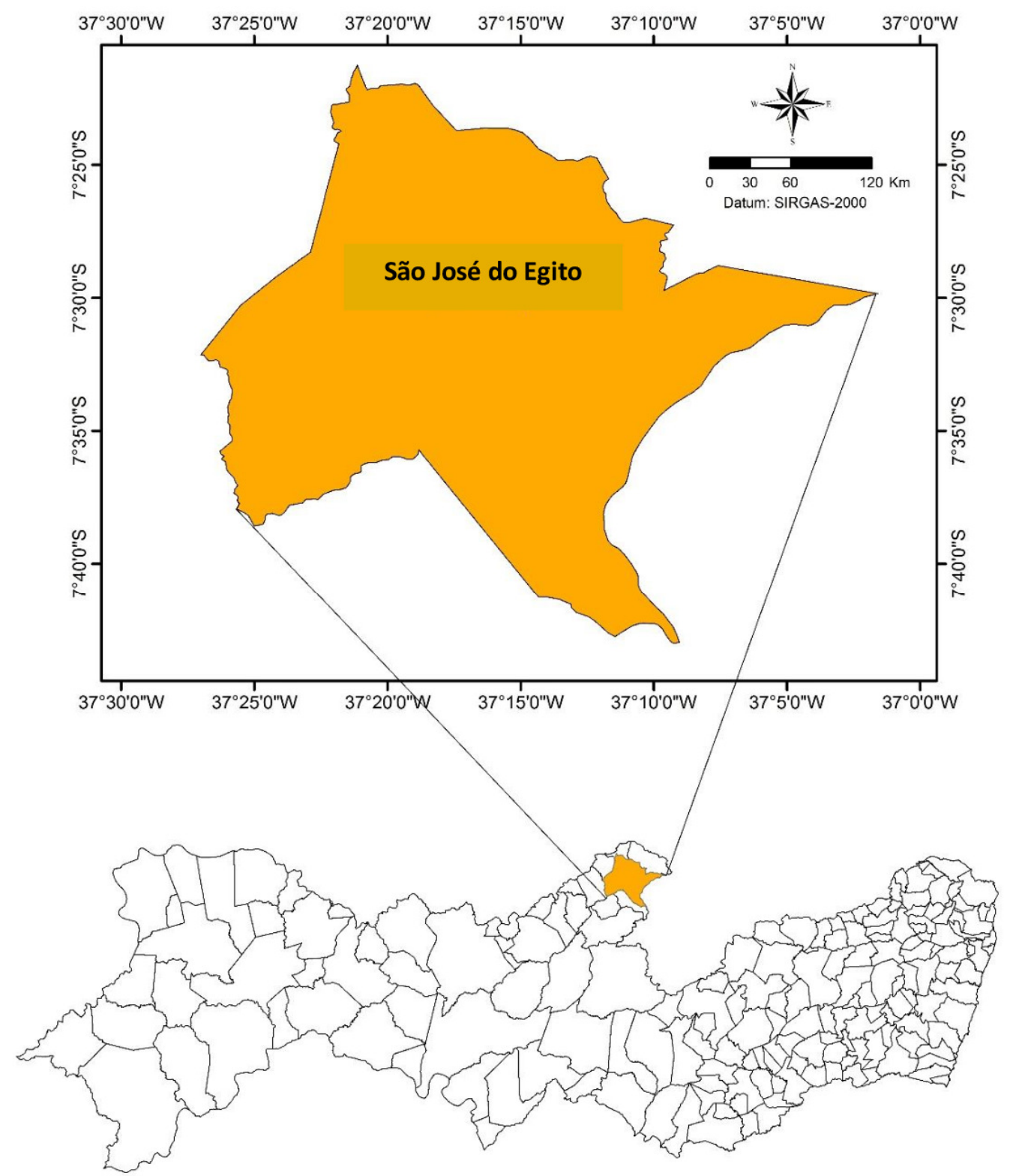

Figura 2. Localização do município de São José do Egito-PE. Fonte: Bilar, A. B. C. (2017).

\section{Resultados}

Ao todo, 58 estudantes com faixa etária entre 11 e 17 anos responderam o questionário, sendo 22 (38\%) do sexo feminino e $36(62 \%)$ do sexo masculino.

Apenas 13 discentes ou $22 \%$ residem no povoado onde a escola está localizada, onde há serviço regular de coleta de lixo. Outros 45 (78\%) moram em sítios próximos, onde não há serviço de coleta de lixo, o qual é queimado ou enterrado; apenas uma pequena parte dele é aproveitada como composto orgânico nas plantações.

Ao serem indagados sobre o conceito de educação ambiental, 23 estudantes ou $40 \%$ responderam que não sabiam do que se tratava, 8 ou $14 \%$ disseram terem estudado antes, mas não lembravam; 27 (46\%) afirmaram saber o significado do termo. Dentre os que disseram ter ciência acerca do que é educação ambiental, as respostas mais frequentes relacionaram-se ao ensino de atividades voltadas à preservação ambiental e ao respeito ao meio ambiente.

Dentre os respondentes, $44 \quad(76 \%)$ afirmaram desconhecer totalmente o que vem a ser sustentabilidade e 14 (24\%) disseram ter estudado anteriormente, mas não lembravam o significado.

A maioria dos estudantes (34, correspondendo a 59\%) informou que a água utilizada para consumo humano em suas residências é armazenada em cisternas. Apenas 24 (41\%) informaram que ela é oriunda de poços.

Coar a água foi apontada como a principal forma de tratamento por $81 \%$ dos estudantes, depois foram citadas a filtragem $(41 \%)$ e a aplicação de cloro por apenas $33 \%$. 
De acordo com 28 estudantes (48\%), parte da água disponível para suas famílias é utilizada para saciar a sede de animais e 27 (47\%) disseram que ela também é usada para irrigar plantações.

Dentre os estudantes que informaram utilizar em suas residências torneira ou chuveiro para fazer sua higiene pessoal, menos da metade (48\%) afirmaram fechar a torneira sempre enquanto escovam seus dentes. Apenas 29\% afirmou que não é sempre que fecham o chuveiro enquanto se ensaboam.

Dentre os 13 estudantes que residem no povoado Curralinho, onde há serviço regular de coleta de lixo realizado pela prefeitura, 10 (80\%) disseram que esses resíduos sólidos domiciliares são encaminhados para o lixão da cidade.

Dentre os respondentes, $64 \%$ citaram como principais consequências do descarte inadequado de lixo: a poluição do ar e do solo, o mau cheiro e os prejuízos à saúde da população (doenças). Destes, $36 \%$ disseram desconhecer quais seriam as consequências.

Ao serem indagados se têm conhecimento sobre o que é reciclagem, $81 \%$ dos estudantes responderam positivamente, e disseram que ela é importante para reduzir a quantidade de lixo descartada no meio ambiente.

Quando indagados se existe o hábito de separar o lixo na escola onde estudam, todos responderam negativamente. Quando o mesmo questionamento foi feito em relação às suas residências, 59\% deram a mesma resposta.

Quando questionados se haviam participado de alguma atividade na escola relacionada ao meio ambiente, $31 \%$ dos estudantes responderam que não e $69 \%$ que sim, estes últimos descreveram estas atividades como sendo: projetos de reciclagem, cultivo de horta, coleta de lixo no entorno da escola e produção de sabão reutilizando óleo de cozinha.

\section{Discussão}

Os resultados permitem constatar que existe uma grande deficiência dos estudantes acerca do entendimento dos conceitos de educação ambiental e, principalmente, sustentabilidade, refletida em hábitos inadequados, causadores de prejuízos ambientais, tanto no que se refere ao uso da água, quanto em relação à destinação dada aos resíduos sólidos domiciliares por eles e seus familiares. Isso vai de encontro às orientações de Oliveira \& Carvalho (2003) acerca da importância da preservação dos escassos recursos hídricos disponíveis no planeta, principalmente no semiárido. Segundo Ribeiro \& Lima (2000), especialmente no que tange aos problemas que o descarte indevido de lixo pode gerar ao meio ambiente e à qualidade de vida.

Foram identificados comportamentos e ações ambientalmente inadequados por parte dos estudantes e seus familiares, como o desperdício de água durante sua higienização pesssoal, a não separação dos resíduos sólidos domiciliares, além do fato daqueles que residem em sítios queimarem ou enterrarem o lixo; apesar da maior parte dos estudantes terem conhecimento acerca dos impactos negativos que essas atitudes podem causar e de ter sido constatado o reaproveitamento de uma pequena parcela desses resíduos como composto orgânico para a agricultura familiar.

A dependência do uso de cisternas e poços por parte dos respondentes em suas residências confirma a vulnerabilidade das estratégias voltadas a mitigar as dificuldades de convivência com a estiagem no Nordeste do Brasil, conforme Rebouças (2002), Cirillo, Góes \& Asfora (2007), Botto, Mota \& Ceballos (2009), Lima, Silva \& Sampaio (2011), Freitas et al. (2012) e Silva et al. (2013).

Verificou-se que o tratamento dado à água armazenada destinada ao consumo humano é inadequado e esse fato aliado à destinação imprópria de resíduos sólidos, em desacordo com a Lei $\mathrm{n}^{\circ} 12.305 / 2010$, pode causar sérios problemas ao meio ambiente e à saúde das pessoas, conforme advertem Mucelin \& Bellini (2008) e Ribeiro \& Rooke (2010).

Atestou-se que São José do Egito/PE, assim como muitos outros municípios brasileiros de pequeno porte com limitações financeiras e técnicas (Lisboa, Heller \& Silveira, 2013), ainda possui lixão a céu aberto, em discordância com o artigo 54 da Política Nacional de Resíduos Sólidos (Brasil, 2010).

Na escola estudada, apesar da existência, segundo a maioria dos estudantes, de atividades relacionadas à educação ambiental, não existe o hábito da separação do lixo, tratando-se de uma falha pedagógica, haja vista que os alunos acabam reproduzindo esse péssimo exemplo em suas residências. Além disso, constatou-se o escasso conhecimento dos estudantes acerca dos conceitos de sustentabilidade e educação ambiental.

Verificou-se que essa instituição de ensino tem difulculdades em atender as diretrizes curriculares para educação ambiental, segundo as quais essa temática deve ser compreendida e inserida de forma integrada, transversal, contínua e permanente em todos os níveis e ensino, conforme os artigos $5^{\circ}$ e $6^{\circ}$ do Decreto $n^{\circ} 4.281 / 2002$ que regulamenta a Política Nacional de Educação Ambiental (Brasil, 2002; 2013) . 
Essa deficiência pedagógica compromete a formação de cidadãos ambientalmente responsáveis, conforme Reis Júnior (2003). Ao mesmo tempo, Brasileiro \& Dias (2013) e Santos \& Barreto (2014) defendem que, consequentemente, se perde uma excelente oportunidade para estimular uma mudança de atitude em direção a uma consciência ambiental pautada por ações sustentáveis.

\section{Conclusão}

A maioria dos estudantes rurais do ensino fundamental compreende os impactos negativos que o mal uso da água e a destinação incorreta dos resíduos sólidos domiciliares podem causar ao meio ambiente e à qualidade de vida das pessoas. No entanto, apesar de possuírem tal entendimento, foram constatados hábitos e atitudes não sustentáveis em relação a esses dois graves problemas ambientais; dentre os quais, merece destaque o desperdício de água, algo inconcebível para habitantes de uma região com enorme escassez de recursos hídricos.

A fragilidade pedagógica demonstrada pela instituição de ensino estudada ao não separar o lixo gerado no próprio ambiente escolar prejudica a formação ambiental de seus discentes, os quais acabam reproduzindo esse hábito ambientalmente inadequado em suas casas. Além disso, há pouca eficácia nas demais práticas pedagógicas adotadas no âmbito da educação ambiental, comprovada pela escassez de conhecimento dos discentes sobre o conceito de sustentabilidade.

\section{Agradecimentos}

Os autores agradecem aos que fazem a Escola Municipal Manoel da Costa, em São José do Egito/PE, pelo apoio durante a realização desta pesquisa, à Fundação de Amparo à Ciência e Tecnologia do Estado de Pernambuco (FACEPE) pela concessão de bolsa de estudos (nível Doutorado) que subsidia a realização dos estudos do segundo autor na região do semiárido pernambucano (bioma Caatinga), bem como ao Conselho Nacional de Desenvolvimento Científico $(\mathrm{CNPq})$ pela Bolsa de Produtividade concedida à terceira autora.

\section{Referências}

BOTTO, M. P.; MOTA, F. S. B.; CEBALLOS, B. S. O. 2009. Efeito da oxigenação por agitação manual da água na eficiência de inativação de coliformes termotolerantes utilizando luz solar para desinfecção em batelada. Engenharia Sanitária e Ambiental, v.14, n.3, p. 347-352.
BRASIL. 1999. Lei Federal n 9.795 , de 27 de abril de 1999. Dispõe sobre a educação ambiental, institui a Política Nacional de Educação Ambiental e dá outras providências. Disponível em: http://www.planalto.gov.br/ccivil 03/leis/L9795.h tm. Acesso em: 10 ago. 2014.

2002. Decreto Federal $n^{\circ} 4.281$, de 25 de junho de 2002. Regulamenta a Lei Federal $n^{\circ}$ 9.795, de 27 de abril de 1999, que institui a Política Nacional de Educação Ambiental e dá outras providências. Disponível em: http://www.planalto.gov.br/ccivil 03/decreto/200 2/d4281.htm. Acesso em: 11 ago. 2014.

2010. Lei $\mathrm{n}^{\mathrm{o}} 12.305$, de 2 de agosto de 2010. Institui a Política Nacional de Resíduos Sólidos e dá outras providências. Disponível em: http://www.planalto.gov.br/ccivil 03/ ato20072010/2010/lei/112305.htm. Acesso em: 10 ago. 2014.

Ministério da Saúde. Conselho Nacional de Saúde. 2012. Resolução $\mathrm{n}^{\circ}$ 466, de 12 de dezembro de 2012. Aprova as diretrizes e normas regulamentadoras de pesquisas envolvendo seres humanos. Disponível em: http://conselho.saude.gov.br/resolucoes/2012/Res o466.pdf . Acesso em: 11 ago. 2014.

. Ministério da Educação. 2013. Diretrizes Curriculares Nacionais Gerais da Educação Básica. Brasília: MEC/SEB/DICEI. Disponível em: http://portal.mec.gov.br/index.php?option=com d ocman \&view=download\&alias $=13677$-diretrizeseducacao-basica-2013-pdf\&Itemid=30192.

Acesso em: 01 maio 2017.

. Câmara dos Deputados. 2015. Projeto de lei $\mathrm{n}^{\circ} 2.289$, de 07 de julho de 2015. Prorroga o prazo para a disposição final ambientalmente adequada dos rejeitos de que trata o art. 54 da Lei $\mathrm{n}^{\circ} 12.305$, de 2 de agosto de 2010. Disponível em: http://www.camara.gov.br/proposicoesWeb/fichad etramitacao?idProposicao $=1555331$. Acesso em: 21 mar. 2017.

BRASILEIRO, E. O.; DIAS, R. 2013. Parceria entre Parques Urbanos e Escolas: Estratégia de Ensino/Aprendizagem na Educação Ambiental Formal. Revista Brasileira de Educação e Cultura, n. 7, p.55-72.

CIRILO, J. A.; GÓES, V. C.; ASFORA, M. C. 2007. Integração das águas superficiais e subterrâneas. In: CIRILO, J. A., CABRAL, J. J. S. 
P., FERREIRA, J. P. L., OLIVEIRA, M. J. P. M., LEITÃO, T. E., MONTENEGRO, S. M. G. L.; GÓES, V. C. (org.). O uso sustentável dos recursos hídricos em regiões semiáridas. ABRH, Editora Universitária da Universidade Federal de Pernambuco. p. 167-175.

CRESWELL, J. W. 2007. Projeto de pesquisa: métodos qualitativo, quantitativo e misto. Porto Alegre: Artmed.

FREITAS, I. M.; BOHRER, C. B. A.; HORA, A. F.; CEDDIA, M. B.; SIQUEIRA, G. M.; GUEDES FILHO, O. 2012. Propriedades físico-hídricas de uma barragem subterrânea no estado do Rio de Janeiro. Revista de Ciência da Vida, v. 32, n. 1, p. 93-105.

GIL, A. C. 2007. Como elaborar projetos de pesquisa. 4. ed. São Paulo: Atlas.

2009. Métodos e técnicas de pesquisa social. 6. ed. São Paulo: Atlas.

IBGE. Instituto Brasileiro de Geografia e Estatística. 2010. Cidades. Disponível em http://cidades.ibge.gov.br/xtras/perfil.php?codmun $=261360$. Acesso em: 11 ago. 2014.

LIMA, A. E. F.; SILVA, D. R.; SAMPAIO, J. L. F. 2011. As tecnologias sociais como estratégia de convivência com a escassez de água no Semiárido Cearense. Conexões Ciência e Tecnologia, v. 5, n. 3, p. 9-21.

LISBOA, S. S.; HELLER, L.; SILVEIRA, R. B. 2013. Desafios do planejamento municipal de saneamento básico em municípios de pequeno porte: a percepção dos gestores. Engenharia Sanitária e Ambiental, v.18, n.4, p. 341-348.

MARCONI, M. A.; LAKATOS, E. M. 2003. Fundamentos de metodologia científica. 5. ed. São Paulo: Atlas.

MOURA, M. S. B. 2015. Pluviosidade e evaporação. Árvore do conhecimento bioma Caatinga. Agência Embrapa de Informação e
Tecnologia.

Disponível: http://www.agencia.cnptia.embrapa.br/gestor/bio ma caatinga/arvore/CONT000g798rt3p02wx5ok0 wtedt3nd3c63l.html. Acesso em: 21 maio 2015.

MUCELIN, C. A.; BELLINI, M. 2008. Lixo e impactos ambientais perceptíveis no ecossistema urbano. Sociedade \& Natureza, v. 20, n. 1, p. 111124.

OLIVEIRA, M. V. C.; CARVALHO, A. R. 2003. Princípios básicos de saneamento do meio. São Paulo: Editora Senac.

REBOUÇAS, A. Águas subterrâneas. 2012. In: REBOUÇAS, A. C.; BRAGA, B.; TUNDISI, J. G. (org.). Águas doces do Brasil: capital ecológico, uso e conservação. 2. ed. São Paulo: Escrituras, p.119-151.

REIS JÚNIOR, A. M. 2003. A formação do professor e a Educação Ambiental. Dissertação de Mestrado em Educação, Universidade Estadual de Campinas, São Paulo, Brasil. 278p.

RIBEIRO, T. F.; LIMA, S. C. 2000. Coleta seletiva de lixo domiciliar - estudo de casos. Caminhos de Geografia, v. 1, n. 2, p. 50-69.

RIBEIRO, J. W.; ROOKE, J. M. S. 2010. Saneamento básico e sua relação com o meio ambiente e a saúde pública. Monografia de Especialização em Análise Ambiental, Universidade Federal de Juiz de Fora, Minas Gerais, Brasil. 36p.

SANTOS, E. C.; BARRETO, M. L. M. 2014. A representação de crianças e adolescentes sobre conceito e formação dos resíduos sólidos. Revista Brasileira de Economia Doméstica, v. 25, n.1, p. 419.

SILVA, M. S. L.; ARAÚJO, A. H. R. C.; FERREIRA, G. B.; CUNHA, T. J. F.; OLIVEIRA NETO, M. B. 2013. Barragem subterrânea: contribuindo para a segurança alimentar e nutricional das famílias do Semiárido Brasileiro. Cadernos de Agroecologia, v. 8, n. 2. 